\title{
Affirmatively Reading Post-consumerism. Distributed Participatory Creativity and Creative Destruction of the Malled Metropolitan Centres of Auckland, New Zealand, during COVID-19 Lockdown
}

\author{
Manfredo Manfredini \\ The University of Auckland, Urban Relational Informatics Lab, School of Architecture and \\ Planning, New Zealand
}

\begin{abstract}
The impact of the progressive spatial financialisation of contemporary on the centres of public life has involved the privatisation of a relevant portion of their social, cultural, political and economic nodes and their polarisation into the private precincts of integrated shopping and entertainment enclosures. This dispossession and dislocation have increased spatial inequality and atomised the networks of local communities. A recent occurrence of creative destruction presided by the inexorable logics of capital reproduction has hit the paradigm that informed these enclosures. The production of the ultimate model of these centres, here defined as ultra-modern centres with totalising superlative simulated civicness, has intimately combined consumption with production in what Ritzer calls prosumption. I submit that the novel prosumer has become a primary actor of dynamic choral practices of semi-complicit participatory consumption that originate counterspatial associative assemblages by articulating three novel digitally augmented phenomena: networked translocalisation, multiassociative-metastable transduction, and desiring-resistant transgression. To validate this hypothesis I set out an observational analysis of grassroots social networks of digital spatialities emplaced in the malled urban centres of Auckland, New Zealand during COVID-19 lockdown, a period of outright access negation to the physical centres of public relational life. Empirical findings not only provided evidence of the formation, high resilience and independence of the novel emplaced translocal networks, but also documented their explicit redistribution of orders of ownership and belonging, and their assertive reappropriation and reassociation of commoning spatialities. The found effectiveness of these assemblages in breaching of the fundamental rule of non-response of dominant powers controlling the places of superlative abstract civicness, deconstructing the dominant spatial logics of the simulative infrastructure that inhibit the elaboration of sign values that affirm the right to identification, and supplementing the postconsumerist use-exchange value amalgamation that sustains the commodity fetishism mechanism of these civic simulacra underpins my critical affirmative interpretation of the post-consumerist condition.
\end{abstract}

Keywords: public space and COVID-19, shopping centres, spatial data analysis, Instagram, Auckland, New Zealand

To cite this article:

Manfredini, M. (2020). Affirmatively Reading Post-consumerism. Distributed Participatory Creativity and Creative Destruction of the Malled Metropolitan Centres of Auckland, New Zealand, during COVID-19 Lockdown, The Journal of Public Space, 5(3), 207-226, DOI 10.3289I/jps.v5i3.I392

This article has been double blind peer reviewed and accepted for publication in The Journal of Public Space. 


\section{Structures and issues in emergent urban centralities}

The process of universal alienation (Harvey, 2018), which includes the progressive spatial financialisation (French et al., 20I I) and obliteration of the commons (Hardt \& Negri, 2009, p. 137) led by dominant class and corporate power with the support of neoliberal governance, has instituted an urbanisation mode of enclavic segmentation (Shane, 2005) that reifies geographically the unbalances in power and wealth of the contemporary strong and rigid social hierarchy. The spiralling spatial inequity of such a molar fragmentation of the urban geography has particularly concerned the centres of public life. A relevant portion of the social, cultural, political and economic nodes have moved into the private precincts of integrated commercial enclosures, such as shopping and entertainment centres. With this migration, public spaces have lost centrality to private quasi-public realms and, with it, reified the influential role of transnational financial organisations of the current financialised mode of urban governance. This dislocating privatisation within the relationally adverse conditions of such commercial environments and the consequent atomisation of emplaced local networks are integral part of the overall spatial restructuring that reflects the increase of vertical social segregation (Harvey, 2006).

In the last decades, the enclosures of consumption have undergone a major systemic reset: a process of creative destruction dictated by the inexorable logics of capital reproduction (Harvey, 2007, 2012; Ritzer \& Lair, 2007). Disruptive digital technologies drive this severe unfolding that has even given rise to the prevision of an imminent outright disappearance of the shopping centre model (Ritzer \& Degli Espositi, 2020). The retail and entertainment sector, the engine of this model, has unrelentingly moved towards online services, intensifying the restructuring imperative which emerged a few years ago with the advent of the experience economy (Pine \& Gilmore, 20I I). The experiential transformation of these centres into "creative" places of eventful consumption (Manfredini \& Jenner, 2015; Voyce, 2006) was inadequate to halt the disruption. Shopping mall corporations have promptly responded with the conception of a radical "spatial fix" (Harvey, 20I2) that lures back customers and revitalises the fading consumption flows in their spaces.

The ultimate model quickly eventuated through the development of an ultra-modern centre with totalising superlative simulated civicness (Manfredini, 2019b). Different from the latest version of the modern shopping and entertainment centre of magic spectacle (Goss, 1993), where the consumer is an upgraded Debordian passive character of a finely tuned and microscripted spectacular eventfulness, the new centre has implemented an intimate combination of distributed consumption and production. The customer has become a primary actor of dynamic choral performances of participatory consumption (Hoyer et al., 2020). Curated coalescences of production and consumption encourage the omnicapable prosumers to proactively engage with and excessively consume the alienated products of their commodified labour (Ritzer, 2014; Ritzer \& Jurgenson, 2010). Enchantment is produced by creating pseudo cities "more real than reality" - cities that break down "the wall of the second dimension, creating not an ... illusion, but a total theatre ... with human beings" (Eco, 1986, p. 45). A theatre where the hyperreal social finds "a sort of effectively realized utopia in which the real emplacements, all the other real emplacements that can be found within culture, are simultaneously represented, contested and inverted" (Foucault, 2008, p. 17). This concrete utopia is Foucauldian heterotopic diapositive that combines illusory and compensatory functions (Foucault, 
2008, pp. 2I-22). Illusions and compensations reinstitute the dispossessed civic self, deploying spatial, social and symbolic simulation means. The simulation subsumes and conflates elements of experientially rich pseudo-urbanity that transcend the real, to produce the hyperreal: a "hallucinatory resemblance of the real to itself" (Baudrillard, 1994, p. 23). Multifarious civic simulacra, the quintessence of Baudrillardian copies without actual reference, stage mise-en-scènes of fascinating fetishes of relationality material, social and cultural - which provide abundant materials for territorial associations and stabilisation of (pseudo)communities of prosumers (Manfredini, 2017). As illusory emplacements, these civic heterotopias institute ideal paradigms of urban space associated to them. Their embodiments expose "all real space, all the emplacements in the interior of which human life is enclosed and partitioned, as even more illusory" (Foucault, 2008, p. 2I). Their materialisation affirms normative discourses on what is desirable or permissible, excluding what is not. The reformist "precession" of these simulacra (Baudrillard, 1994, Pp. I-42) is reinforced by their compensatory function. Concrete ideals are introduced in the everyday practice as instances of perfected mundane reality, constituting other places of meticulously constructed reality showing how "ours is disorderly, ill construed and sketchy" (p. 2I). Embracing participatory consumption, these malls fully accomplish the task of commodifying the civic, promote ultra-consumption, take possession of collaborative creativity and exploit free labour (Ritzer \& Degli Espositi, 2020). However, within this process initiated by the modern mall, by replacing and vigorously activating the entire social, communal, cultural and recreational infrastructures and practices of the city, there is more than assimilation and complicity with the hegemonic logics (Miles, 20I2). Everyday practices in the spatialities of the ultra-modern enclosure exceed the realm of exchange value of commodities. Pleasure and, most importantly, desire are basic materials for the elaboration of sign values that foster transgressive reidentification processes that disband the commodity fetishism mechanism making sign-value a "supplement or super-signifier of use-exchange value" (Miklitsch, 1998, p. 4). Pleasure and desire liberate the relationality elicited by the "space of appearance" (Arendt, 1958) from the controlled interfaces between the quasi-private and the quasi-public.

(Antagonist surrogate or simulated facilities include also those of private domestic practices, particularly effective in the sectors of wellness, conviviality and children care; Manfredini, 2019a).

The prosumer of the ultra-modern simulacra of superlative civicness experiences a new form of engagement. Their post-consumerist behaviour combines three pervasive phenomena of the digital age that foster reproduction of socio-spatial relationships: networked translocalisation, as relational mobilisation of emplaced assemblages; multiassociative-metastable transduction, as recombinant mobilisation of networked presences; and desiring-resistant transgression, as positive dissociative of coded systems. Networked translocalisation is the constant revolution of territorialisation patterns due to an increasing mobilisation of people and things variously related in productive concatenations. While the constant process of transfer and occupation across expanse spaces and on all spatial scales, from the local to the global, challenges both spatial and temporal stability of these concatenations (Deleuze \& Guattari, I987, pp. 35I-423; Kazig et al., 2016), digital technologies have enhanced cohesion and interaction of translocal networks, especially those of the "have-less," who chiefly depend on "an informational dimension - the commingling of critical information across time and space 
- which almost always contextualises and conditions the movement of people, goods, and services" (Cartier et al., 2005, p. 14). A typical example of the new mall's outpacing environment to networked translocalisation is the capacity of their material and symbolic patterns to constitute workable conditions for the emplacement of mobilised actants.

Multiassociative-metastable transduction involves the establishment of assemblages through transmutative relations that operate simultaneously on representation and production realms (Guattari, 2006, p. 258). Iterative systems of relations bring together distributed and heterogeneous elements in disjunctive relationships of concatenations that restructure local conditions and contexts. Since the realms produced by these concatenations instituted by iterative relational systems are determined by their status the transformative effect is metastable, as it persists only when the systems are activated. The inborn capacity of virtual, augmented and mixed realities to bring together heterogeneous elements across different domains with progressive speed and efficiency makes contemporary transduction instances increasingly immersive and evenemential (MacKenzie, 2006). A typical example of the new mall's outpacing relational spatialities is the growth of nodes of social networks that progressively gain centrality due to the combination of the metastable relations between their translocalised members and the reterritorialising (i.e., pseudo-associative and hyperidentifying) properties of their simulacra.

Desiring-resistant transgression is a widely diffused agent of translocalised urbanites who deploy "shared symbols, subversive recodings, and semiotic inversions of the existing order" (Ferrell, 20I I, p. 56I) to deconstruct and challenge existing structures. "Agonistic" (Mouffe, 1999) counterspaces are produced informally or illicitly at the margins of society to favour autonomy and spontaneous forms of self-organisation to resist or oppose apparatuses of domination (Figure I). Particularly active in the digitally enhanced world of Mediapolis (de Jong \& Schuilenburg, 2006), this dissociation of coded systems is the key to set off or strengthen forms of becoming that produce the vision, creation and presentation of alternative systems of identification, meaning and representation (Ferrell, 20I3). A typical example of the new mall's outpacing agential capacity is the resistance to congregation bans implemented with explicit codes of conduct that prosumer communities enact with intense activity on emplaced social media networking.

These three phenomena have critically contributed to create conditions that can oppose the fragmenting agency of the quasi-public space of the mall. The realityvirtuality continuum (Milgram et al., 1995) that they have implemented forms a highly performative interconnected hybrid realm that can counter the segregational power of the enclosures. The combined forms of digitally enhanced translocalisation, transduction and transgression can operate to reinstate their space of flow in the political sphere. Locative mobile social media applications (e.g., Twitter, Instagram and Sina Weibo) enable the simultaneous presence and action of local and remote actors, including the translocal, the marginalised and the antagonist. These platforms build relational capacity of the individual and collective prosumers to independently reappropriate and reassociate the abstracted territories of their daily life (Manfredini, n.d., 2017). 


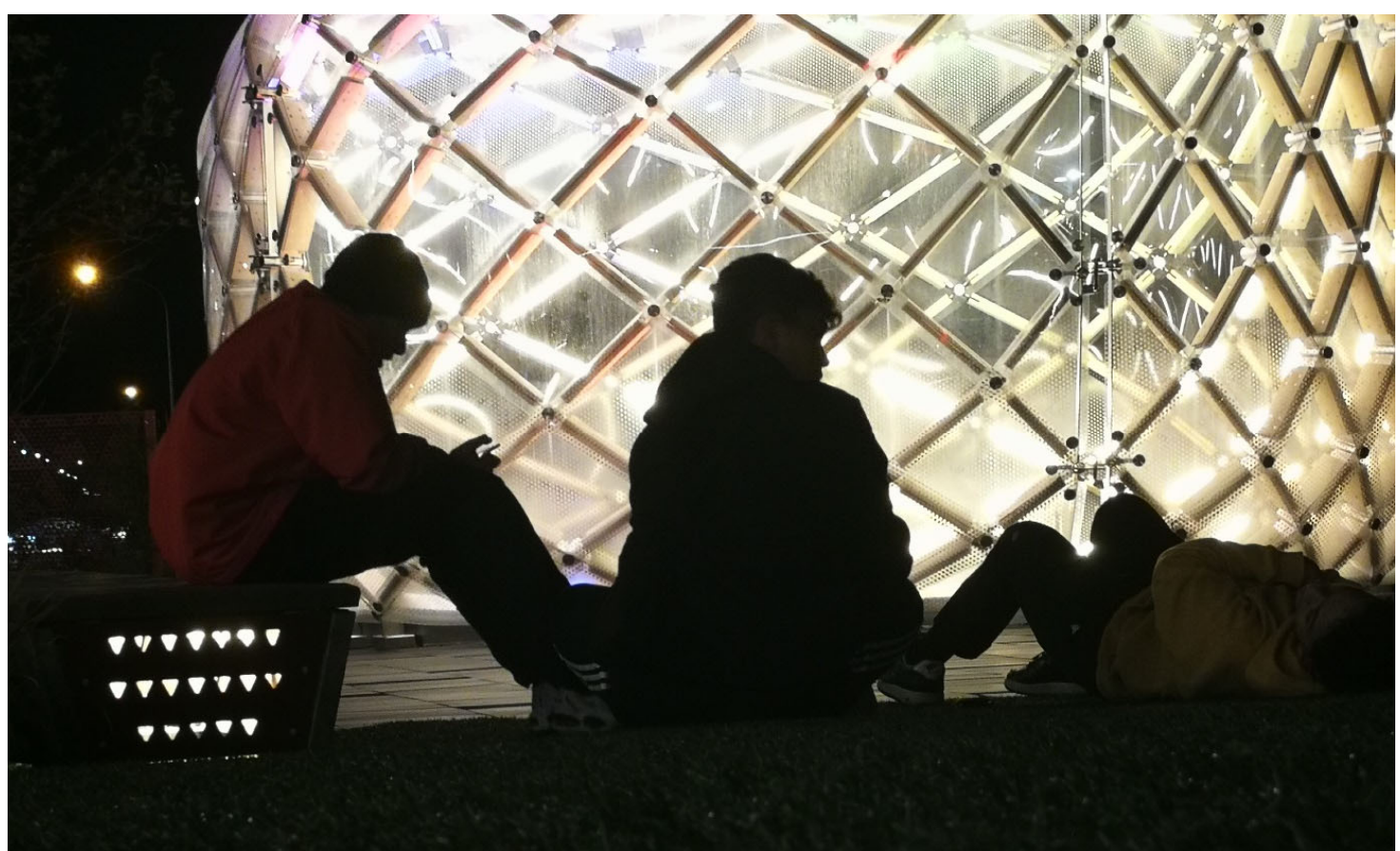

Figure I. Irregular spatial practices: "non-compliant" appropriation of consumers in the theatron in the luxuriant open theatre of the "Grove," the new lifestyle dining district of Auckland's Sylvia Park Shopping Centre (M. Manfredini, 2020)

COVID-19's mobility and gathering restrictions have caused major social, political, and economic deprivations. The height of both cultural and material disciplinary regimes deployed by the state to negate access to urban space has shown the enormous hardship of urbanites dispossessed of the emplacements of their relational spheres. Surrogate digital spatialities have partially compensated for the loss, but have dramatically expanded the existing inequalities. Exacerbations have included the disruption of the public space-dependent informal economic sector caused by the failure of economic governance to mitigate the asymmetrical systems of social protection (OECD, 2020), and the increase of social exclusion caused by the inefficacy of governing bodies in moderating the effects of the divide in the digital "pulsing field of tension" on the morbid multidimensional isolation of individuals (Sloane, 2020).

In the new simulated commons, the effects of this crisis have been even higher.

Proactively confirming the capacity of their simulacra to precede and preempt those of the rest of city beyond their boundaries, the malls instantly responded with a total and politically unchallenged interdiction of their quasi-public spaces. Fencings were promptly erected and invigilators to reinforce the panoptical control with 24 hour CCTV surveillance introduced (Figure $I$ and 2). Communication reaffirming the normativity of the new normal with imposing billboards elaborating deferential "public wellbeing" narrative followed suit (Figure 3 ) The disruption deformedly mirrored by the total space of the mall not only occluded their mediated space, richly supporting transduced social networks by shutting down the metastability of their social spatialities, but also completely obliterated the informality of its externalities, such as the translocal and multicultural bottom-up daily and nightly impermanent markets grown at their margins (Tan, 2020). 

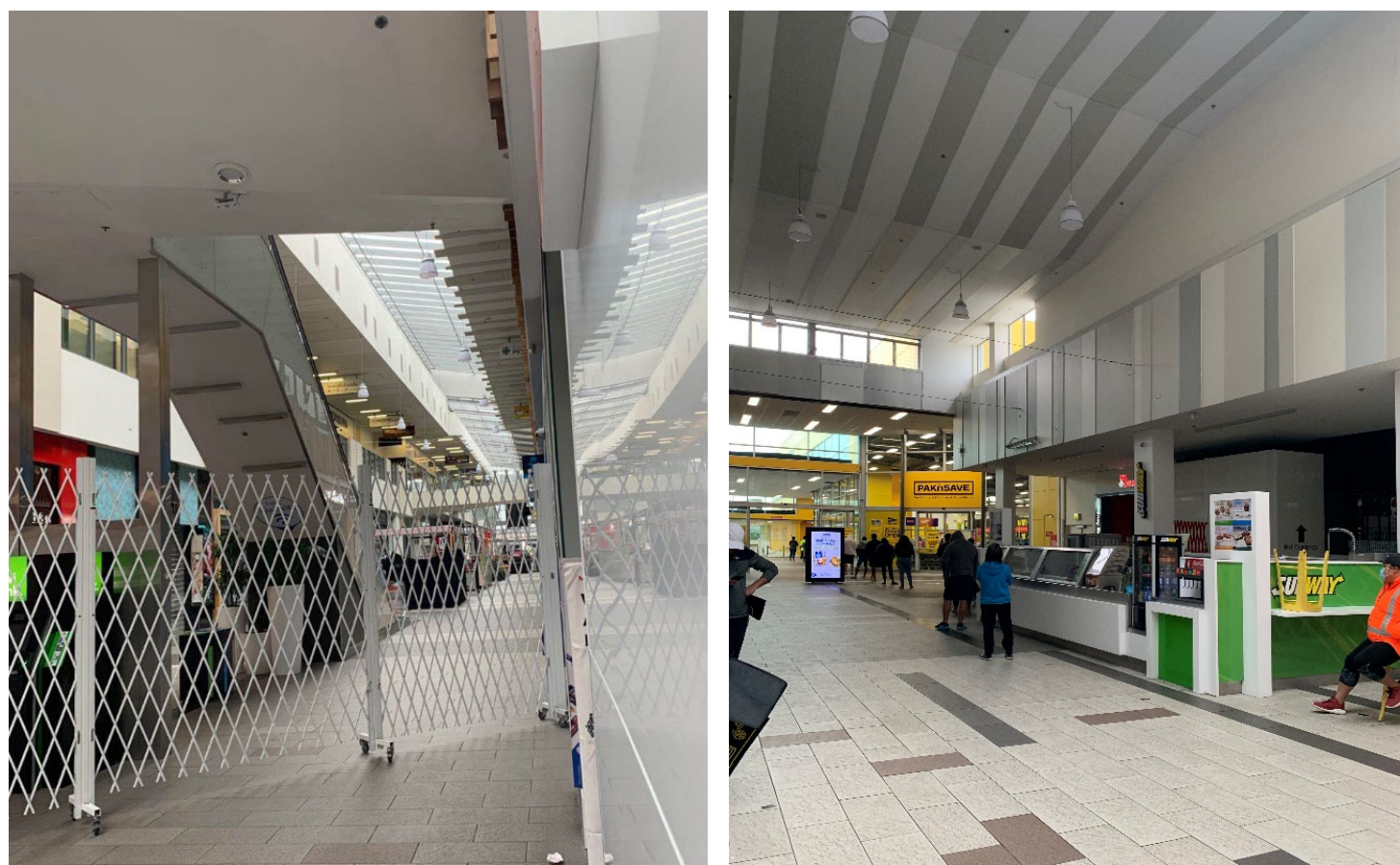

Figure 2. The securitised Sylvia Park Shopping Centre, Auckland's premiere ultra-modern mall, during the strict lockdown of Alert Level 4 - Eliminate: Instant fencing off of the main arcade (left), (J. Rong 2020), and invigilated distanced queues to the supermarket, the only large facility open during lockdown

(J. J. Rong, 2020)
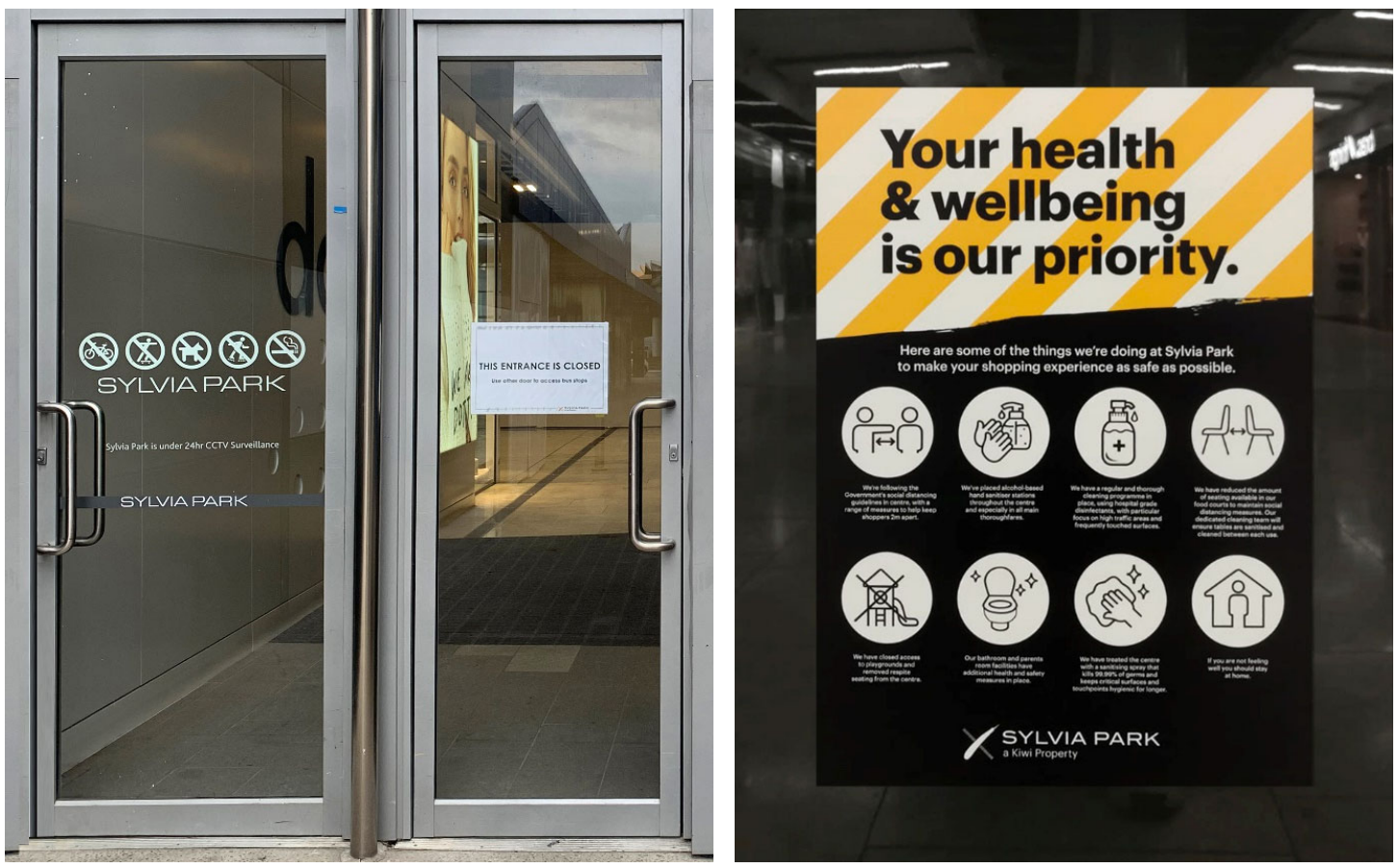

Figure 3. The securitised Sylvia Park Shopping Centre: access interdiction to a corridor connecting to the local surface public transport stop (centre), and customer information billboard during Alert Level 2 Reduce (M. Manfredini, 2020). 


\section{Auckland's malled urbanism under COVID- 19}

The New Zealand response to the pandemic has been internationally recognised for its early success in "crushing the curve" of coronavirus's infection (WHO, 2020).

Restrictive measures, based on a four-tier alert system framework whose highest level, "Eliminate," introduced a strict lockdown at a very early stage, resulted in a swift regression of the transmission rate (Ministry of Health Manatū Hauora, 2020a, 2020c) (Figure 4).
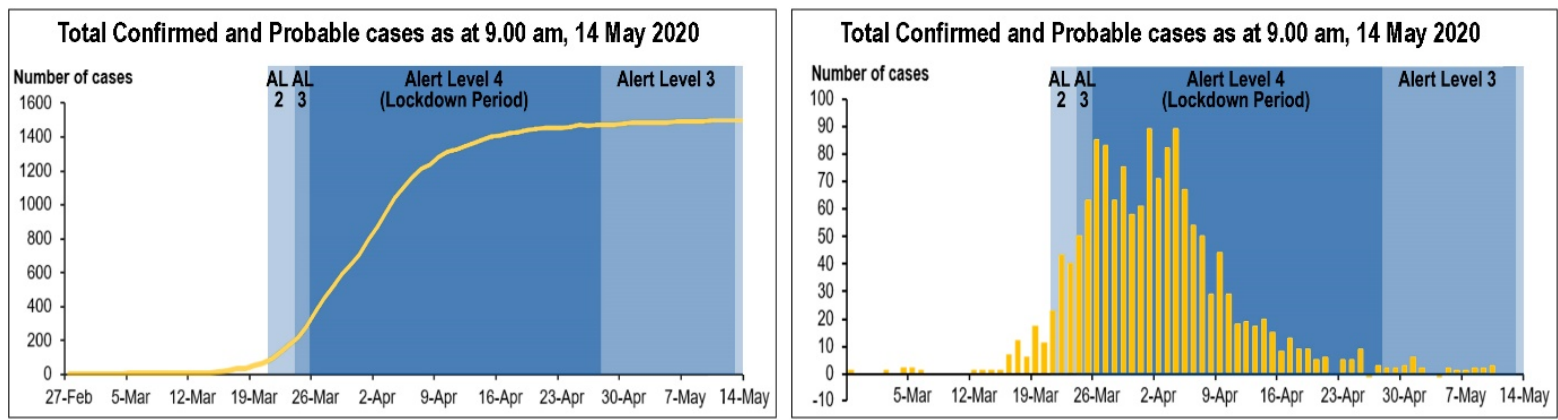

Figure 4. New Zealand coronavirus epidemic curve (Ministry of Health Manatū Hauora, 2020a)

The suppressed transmission prevented a crisis of the health system, contained the number of fatalities and led to the loosening of the restrictions and the adverse social, psychophysical and economic impact of prolonged isolation (Ministry of Health Manatū Hauora, 2020b). The high compliance of the public was buttressed by policies that involved substantial investments - larger than in most of the other advanced international free-market economies, when compared to GDP (The Treasury Te Tai Ōhanga, 2020) - prioritising people's welfare, wages, income.

This early action undertaken against the pandemic eventuated in a peculiar distribution of the infection. Substantially inverting the New Zealand's structural socio-economic inequalities in health (Wilson et al., 2018), the most affected by the virus were the privileged, belonging to the ethnic group with the highest income, which outnumbered by far all other groups combined (Ministry of Health Manatū Hauora, 2020a; Stats NZ Tatauranga Aotearoa, 2020). With regard to age, the distribution of cases was aligned with global figures, showing the highest percentage of cases, $23 \%$, among millennials in their 20s (Ministry of Health Manatū Hauora, 2020a). Geographically, the incidence of the infection has been uneven too. The largest concentration was in urban areas, headed by Auckland, the largest city in the country, accounting for $36 \%$ of the cases. The main public space where the most affected by the pandemic gravitated is located in the major urban centres. Most of these centres are interspersed throughout urban Auckland: an area home to one-third of New Zealand's population with low and distributed density with limited efficiency of urban and social infrastructural systems and an increasing geographical polarisation of socioeconomic inequalities (Terruhn, 2020). Decades of neoliberal regimes have weakened the civic role of the older centres and their commons, enabling their dislocation and financialisation within new locally disconnected urban malled sub-centres, which are dominated by large enclosures for shopping and entertainment, and incorporate a large part of the local social infrastructures (Manfredini \& Jenner, 20I5). 


\section{The digital spatialities of the apparatuses of totalising superlative simulated civicness during lockdown}

To shed light on the contemporary Auckland's public space condition during COVID-19 lockdown, an impromptu exploratory study set out to study the emerging relations between novel spatial structures and daily practices. It focused on the transformation of the emplaced public sphere during the contemporary paradigm change in the mall sector. The penetration of the novel sociospatial civic simulacrum model into the local environment has already resulted in the redevelopment of its main malls. A confirmation of this is offered by Kiwi Propert Group, the owner and manager of the main centre of the city. In the opening statement of the dedicated corporate webpage, it explicitly declares that "developed ... between 2006 and 2007 [the mall] and has since grown from New Zealand's largest shopping centre to a thriving mixed-use community" (Group, n.d.). The outright negation of public, material, emplaced relational spatialites during the early New Zealand COVID- 19 lockdown offered the opportunity to study the effects of an exacerbation of the public space deprivation progressively brought about by the universal alienation process (Harvey, 2018). The lockdown restrictions aggravated the already reduced accessibility of the local communities to the displaced malled centres - a distinctive element of the progressive sociospatial fragmentation and financialisation of everything that obliterates commoning in public space (Figure 2, 3, and 5).
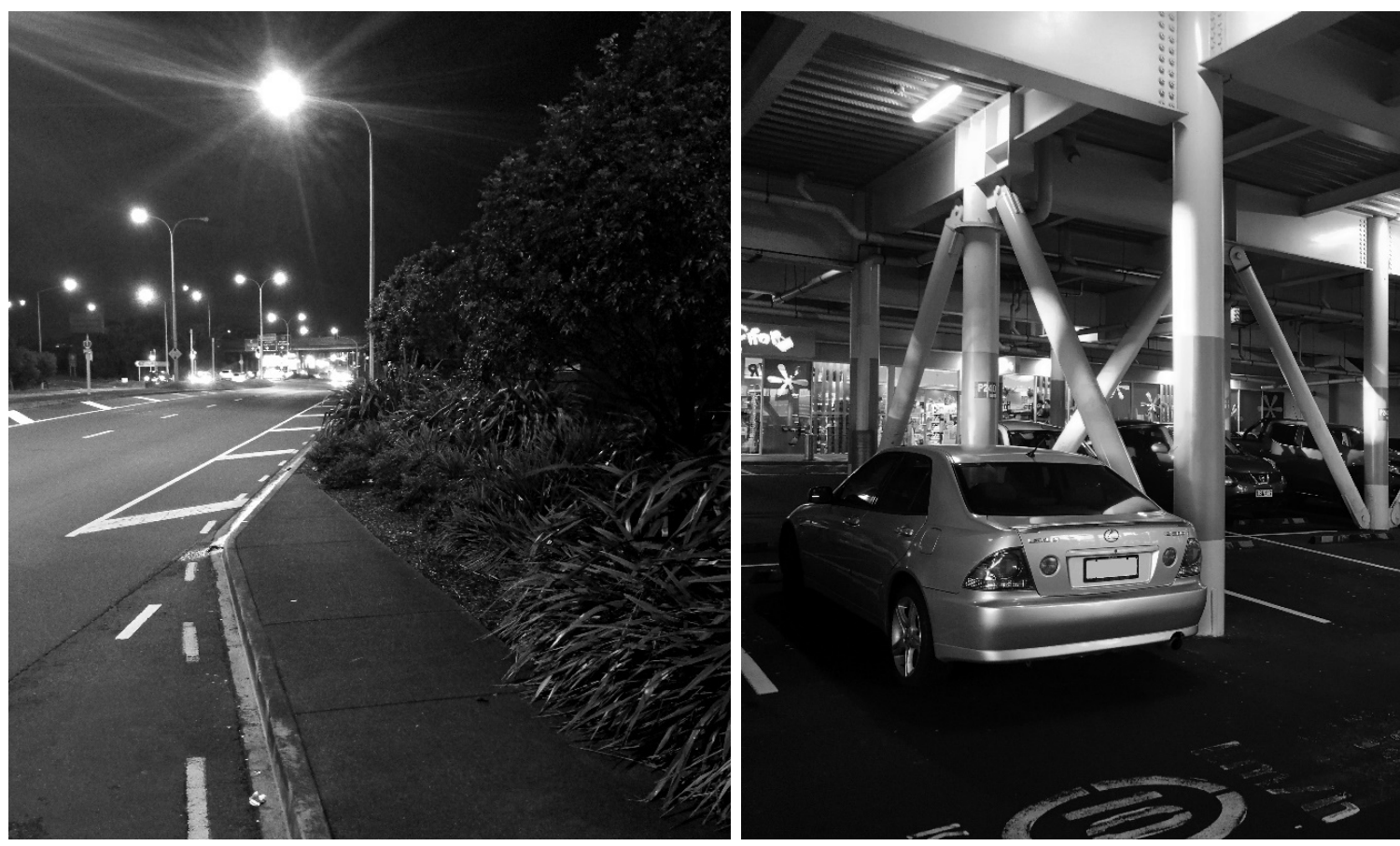

Figure 5. Pedestrian aversions of Auckland's fully malled centres: A sidewalk to "Erewhon, or, Over the Range" (Butler, 1872) in a central section of the movement network in Sylvia Park's Metropolitan Centre (left; M. Manfredini, 2020), and one of the main entrances of shopping centre in St Lukes Town Centre (right, M. Manfredini, 2020).

The study utilised the comparative research methods developed at the Urban Relational Informatics Lab of the University of Auckland (URIL, n.d.) for the Give Us Space research project. This set of methods unveil the effects of networked translocalisation, multiassociative-metastable transduction and desiring-resistant transgression (Manfredini 
et al., 2019) on network formation and spatial perception in hybrid actual-virtual spatialities using crowdsourced data from Instagram, the most popular geolocated visual-based social media (Statcounter, 2020).

The analysis was conducted on two centres of contemporary Auckland's malled urbanism model: the Metropolitan Centre of Sylvia Park (hereafter Sylvia Park) and Westfield St Lukes Shopping Centre (hereafter St Lukes). These cases are the best representation of statutory designated fully malled urban centres - respectively a metropolitan Centre and a Town Centre (Figure 6 and 7).

Sylvia Park is the premier example of integrated ultra-modern mall of superlative simulated civicness. The mall, a Regional Centre with gross lettable area of $86,427 \mathrm{sqm}$, was opened in 2006 and constantly upgraded and expanded (the recent additions include also one open-air lifestyle precinct with green and cultural spaces). Its owner and operator, Kiwi Property Group owner has a portfolio including 6 shopping centres (FigureFigure 7 7). Westfield St Lukes Shopping Centre (hereafter St Lukes) is a good example of the modern mall. This mall, a Sub-Regional Centre with a gross lettable area of 39,479 sqm, was built in 197I, converted into a Town Centre with a Plan change in 2010 , and has currently a major redevelopment project in the pipeline (FigureFigure 7 7).

The study had the following operating question and subquestions:

- Has the temporary outright negation of public, material, emplaced relational spatialites during the early New Zealand COVID-19 lockdown revealed the formation of digitally emplaced relational practices that oppose the modern progressive obliteration of the urban commons, which is epitomised by ultra-modern mall - the ultimate apparatus of totalising superlative simulated civicness?

○ Have the networks of the digital public sphere emplaced in the ultra-modern centres during the early New Zealand COVID-I 9 lockdown showed a distinctive behaviour that indicates forms of emancipation of spontaneous social networks from the total control of the apparatuses of the socially adverse civic simulacra that have colonised them?

- Have the communicative acts of the digital public sphere emplaced in the ultramodern centres during the early New Zealand COVID- 19 lockdown showed instances of territorial appropriation and association that indicate the emersion of antagonist deterritorialising practices of socialisation, civic cohesion, community connectedness and commoning?

Data analysis and interpretation concentrated on the detection of relationships between different forms of interaction by dissecting their networks to identify their socio-spatial reproduction capacity.

The selected centres best represent the comprehensive spatial sublation of the COVID19 lockdown. Their fenced-off squares, lanes, atria and corridors deserted, with the exception of supermarkets and pharmacies, the only large facilities open during lockdown (Figure 2). Their (dis)location makes them particularly relevant to this study as the profile of their primary users include both those most affected by the pandemic the privileged, the young adults and the urbanites - and the most avid users of digital media services - those who massively turned to social media to maintain their networks when their face-to-face interaction was drastically interrupted (Statcounter, 2020). 


\section{Affirmatively Reading Post-consumerism}

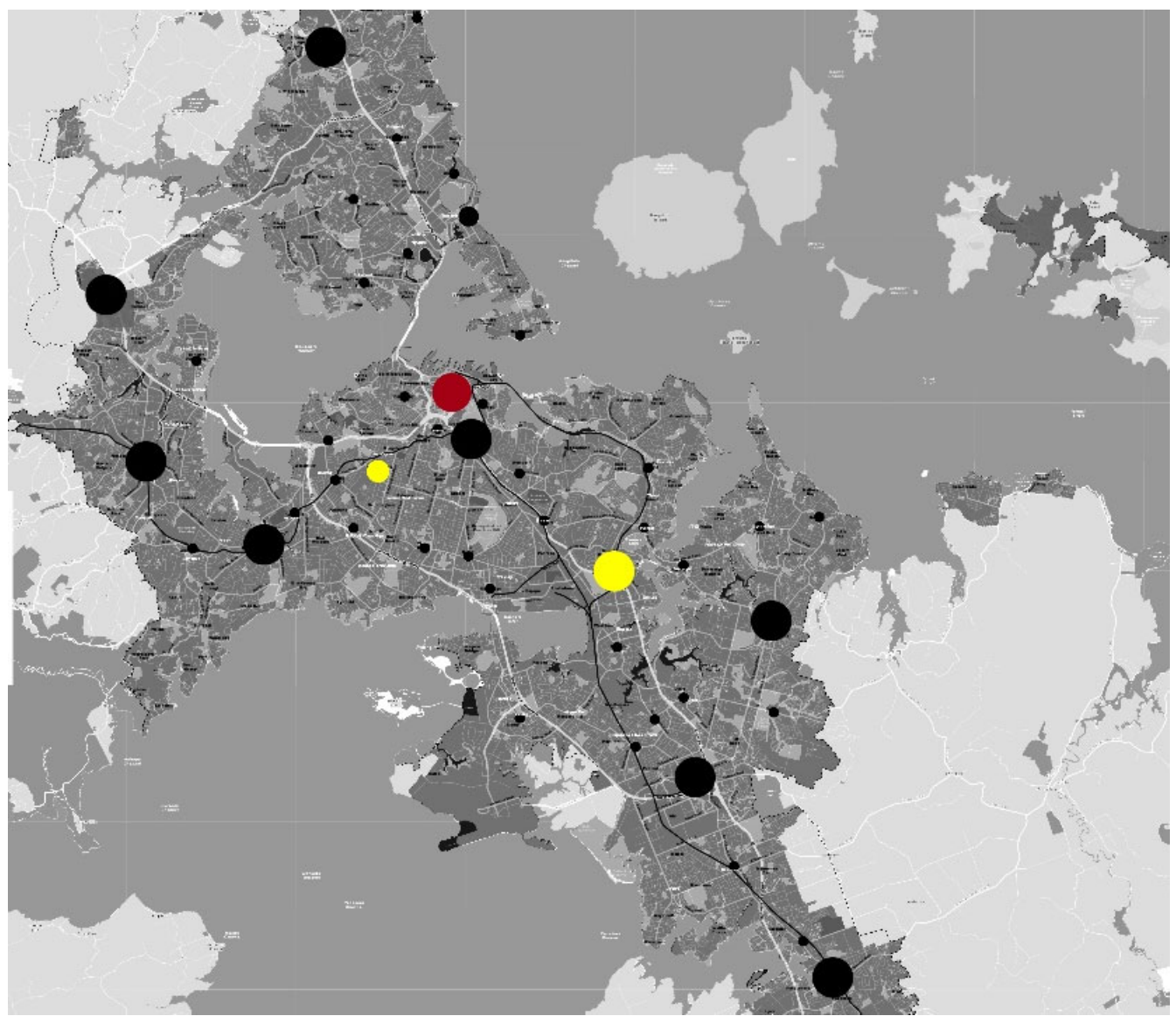

Figure 6. Auckland Plan 2050: Development Strategy. Map showing the City Centre (red circle) and the nine Metropolitan Centres (large black circles with Sylvia Park in yellow) and the town centres (small circles with St Lukes in yellow), (Auckland Council, 2012; adapted by the author).
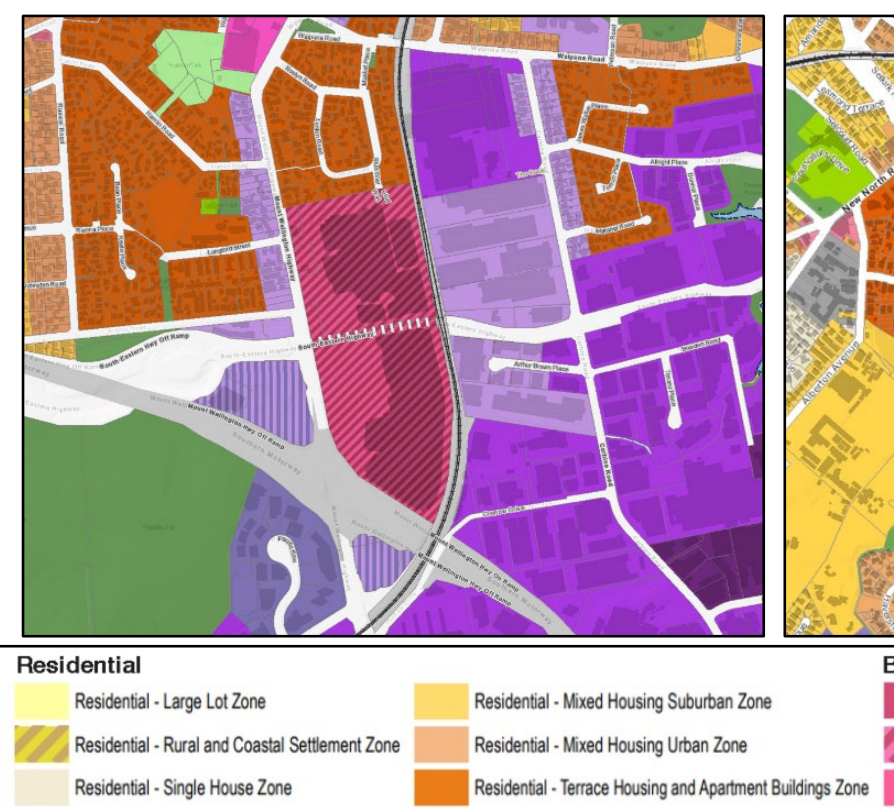

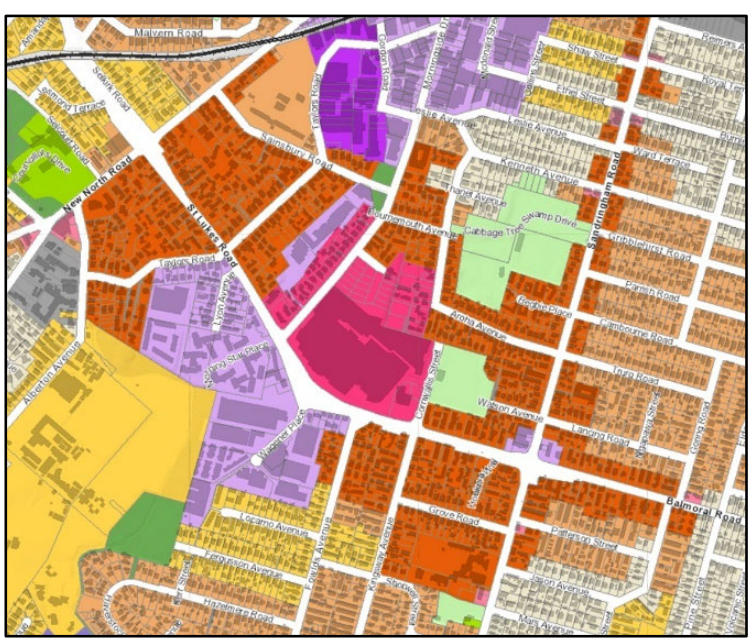

Business

Figure 7. Zoning the mall as urban centre: Auckland's Sylvia Park's Metropolitan Centre (left) and St Lukes Town Centre (right) in the Auckland Unitary Plan (Auckland Council, 2020; adapted by the author).

216 | The Journal of Public Space, 5(3), 2020 | ISSN 2206-9658

City Space Architecture / UN-Habitat 
Data collection and processing

Crowdsourced data were collected from the points of interest (POI) located in the two centres. Data included metadata and content of public posts and related interactions (as with many other social media platforms, Instagram engages the user in three modes: author, commenter and liker). Data of the posts was categorised and systematised, as in the previous research (Bueno et al., 2019; Manfredini et al., 2019), including ID data (post URL, date and author's username), media content (images and videos), captions (content of text and hashtag/s), comments (number and username of commenters and text of the comment), and likes (number and username of likers). Data were collected in two periods of equal length, the 33 days of the lockdown period (26th March to 27th April included) and the preceding 33 days (22th February to 25th March included). The URLs were included to enable quick access to posts at any stage during the analysis, as well as providing a base for further information retrieval.

POls were selected through a preliminary analysis of their activity. Each centre included multiple POls with very different usage frequency, most with very low or moderate activity. In each case study, one POI had users greatly outnumbering all the users of the other POls combined. Most of the latter had one single main user, who was usually associated with a local business and shared content polarised around it. Overall, this confirmed the findings of previous longitudinal research conducted on the same malls (Bueno et al., 2019; Manfredini et al., 2019), showing a positive correlation between location tags' popularity and three variables: descriptive efficiency, frequency and diversity of commercial activation. Descriptive efficiency refers to the degree of comprehensiveness and unambiguity of the hashtag name, which favours retrievability and recognition of the place amongst the public. The frequency and diversity of commercial activation of their domains refers to the intensity and variety of the spectrums of promoted products and services, recurring activities and special events, which sustain public interest and engagement. The analysis also showed that the proportion of commercial activity in the most popular tags is rather small. Given these findings, the analysis concentrated on the most popular location tag of each case study: "Sylvia Park Shopping Centre" for Sylvia Park and "Westfield St Lukes" for St Lukes. The quantity of their interaction guaranteed their representativeness. The prevailing presence of non-commercial activity in their domains reduced the risk of inaccurate evaluation of the independent activity.

Data-cleaning minimised non-autonomous, redundant and irregular interaction instances in posts, comments and likes. Items of a commercial origin were recognised and coded manually by triangulating information from different sources (username, visual content and caption often explicitly reveal their origin) and evaluating posting intensity and frequency (commercial activity tends to be greater in quantity and regularity). Findings were validated by accessing previous activity of the Instagram account of the authors (accounts established for marketing purposes consistently pursue their commercial scope). Redundant instances were detected as multiple, superfluous or vain data in protracted comment trails. This was also addressed in the network analysis by using the number of commenters instead of that of comments. Irregularities in posts, likes and comments, such as duplications (reposting of visual content), were also identified and excluded. Abnormal posting, commenting and liking were not considered valid grounds for exclusion (this was the case of one post uploaded during the lockdown which received an exceptionally high number of likes but an average number of comments). 


\section{Findings}

The overall engagement analysis focused on non-commercial data. Findings showed relevant differences of intensity and distribution of interaction instances between the two case studies in the comparison of both the total activity and its variation between the two analysed pre-lockdown and lockdown periods.

The networks emplaced in Sylvia Park maintained a sustained activity, confirming the high engagement of their digital communities (detected in a previous longitudinal study at Urban Relational Informatics Lab, URIL, n.d.). The average daily activity in the analysed period was of 137.9 instances (9102 in total). The lockdown period had only a moderate reduction (-10.5\%), with the number instances moving from I45.5 (4,804 in total) during pre-lockdown to 130.2 (4,298 in total) during lockdown. The variation resulted from a decrease of instances that was sharp in the primary (-75.7\% posts) at and secondary textual (-43.39\% comments), and minor in secondary appreciative $(-7.4 \%$ likes). The ratio of secondary per primary instances showed a strong increase (from 32.4 to 121.8$)$ both in textual $(+124.7 \%$ comments per post) and appreciative $(+281.1 \%$ likes per post) (Figure 8).

The networks emplaced in St Lukes had a comparably lower interaction intensity, with an average daily activity of 29.8 instances (1973 in total). This activity sharply decreased from 4I.2 (I,367 in total) during pre-lockdown to I8.4 (606 in total) during lockdown. The sharp decrease in total interactions $(-55.7 \%)$ resulted from a sharp decrease across all instances (primary $-66.7 \%$, textual secondary $-79.5 \%$ and secondary appreciative 52.3\%) (Figure 8).

The structure of the digital network was explored by addressing the relations between users. This analysis concentrated on Sylvia Park, as the limited quantity of data available for St Lukes undermined analytical reliability and validity. The role of individuals in the networks was investigated by analysing the relationship between them (i.e., the interaction links via comments or likes). The centrality of each user was estimated by assessing the intensity of interactions and the reach of their links. A visualisation of these patterns was obtained by plotting graphs that use nodes and edges as in previous research (Bueno et al., 2019). A node represents an Instagram user who is either an uploader, a commenter or a liker. An edge is the link connecting two nodes and indicating the relationship between them. Subsets for nodes and edges were formed. The node sets included categories for ID number, label (username) and type (poster, commenter or liker). The edge sets included directions, with source and target associated with ID numbers. Sources are poster nodes, targets are either commenters or likers who have interacted with the post nodes. Different graphs displaying the total size of the networks were produced for the pre-lockdown and lockdown periods. In this bimodal network built upon nodes and edges, indication of centrality is determined by the number of immediate connections that associate the nodes. As the data collection captured Instagram users receiving and giving out comments and likes, the immediate links of a node could point towards or away from it. In this analysis, the centrality degree is measured in two different ways: indegree and outdegree centrality. The former represents the amount of connections directed to each node, while the latter corresponds to the number of connections departing from each of them. The graph uses size variations to represent change in the centrality value of each node (change in value is proportional to the change in size), adopts different colours to distinguish poster-nodes and liker/commenter-nodes, and displays the direction of 
connections using arrows. Findings show a strong difference between the pre-lockdown and lockdown structures and centrality patterns of the networks. As is visible in the graphs, the distribution of edges is relatively even in the former and strongly polarised in the latter. The strong polarisation in the lockdown map is determined by the limited number of sources which, consequently, have a much higher level of indegree centrality (Figure 9).

Commercially driven interaction, though not central to this study, provided relevant side information. Analysis showed significant differences between the two case studies. In Sylvia Park this kind of activity was minimal during the pre-lockdown and almost disappeared during lockdown (it moved from $4.2 \%$ to $0.3 \%$ of the total). No evidence was found of commercial activity generated by the central mall management. In St Lukes it had high intensity during the sublation pre-lockdown ( $24.8 \%$ of the total interaction) but it substantially dropped during lockdown (3.8\%). This prominence of commercial posts is sustained by the intense activity of the mall management, which included the best part of the 474 commercially driven interactions generated over both periods. Comparatively, the difference between the two malls may be ascribed to the larger marketing capacity of the management of Scentre Group over that of Kiwi Property Group.

The content analysis on visual data of representational space was concentrated on Sylvia Park, for the same reasons informing the centrality analysis. It primarily considered the lockdown period, to shed light on the nature of the spatial referentiality of the inaccessible spaces of the centre. Based on previously utilised methods (Manfredini et al., 2017), the data were used to detect representations of spatial instances that identify meaningful places of the centre. This involved triangulating information from different sources: images and videos, captions, comments, hashtags and, when necessary, previous activity on the Instagram account of the users. Spatially relevant posts were coded as such and further analysed to determine the most relevant characteristics of placeness based on their capacity to represent identifiable and meaningful material: social and cognitive spatialities of the site in its everyday becoming. The comparison of findings with previous research (Manfredini et al., 2019), showed an unusually high prevalence of spatially relevant posts (83\%) over the usually predominant generic content focused on goods and services provided by the centre, such as food, garments and personal care. Further analysis of the spatially relevant posts revealed another atypical characteristic: the outnumbering proportion (44\%) of visual content originated from personal experiences of the centre produced before the lockdown rather than those produced during the lockdown (39\%) (Figure 8). Most of this content not only deliberately represented locally situated events, but moments of strong personal involvement with the context, when the centre had normal operations (Figure 10). The remaining spatially relevant content was chiefly composed of images, probably concurrently created and posted, representing highly identifiable spaces of the centre in the peculiar lockdown situation (the most common case being long queues of distanced people waiting to enter the only major open amenity, the supermarket, in the extensive corridors and sidewalks under both in-person and remote security surveillance). 


\section{Affirmatively Reading Post-consumerism}

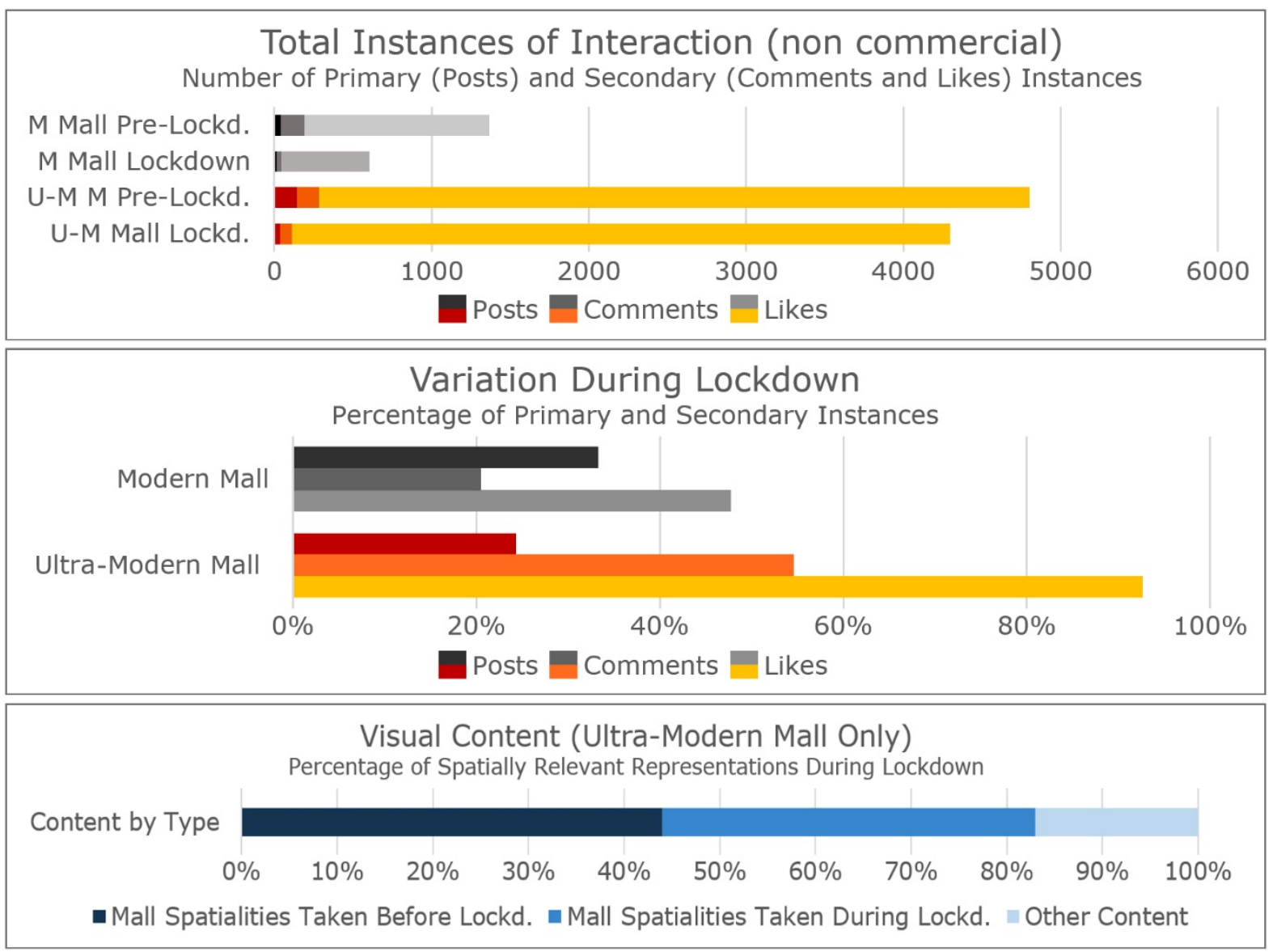

Figure 8. Emplaced digital activity (Instagram data): user interaction instances during pre-lockdown and lockdown (top) and their variations (middle); visual content by type

(J. J. Rong, J. Y. Ye and M. Manfredini, 2020)
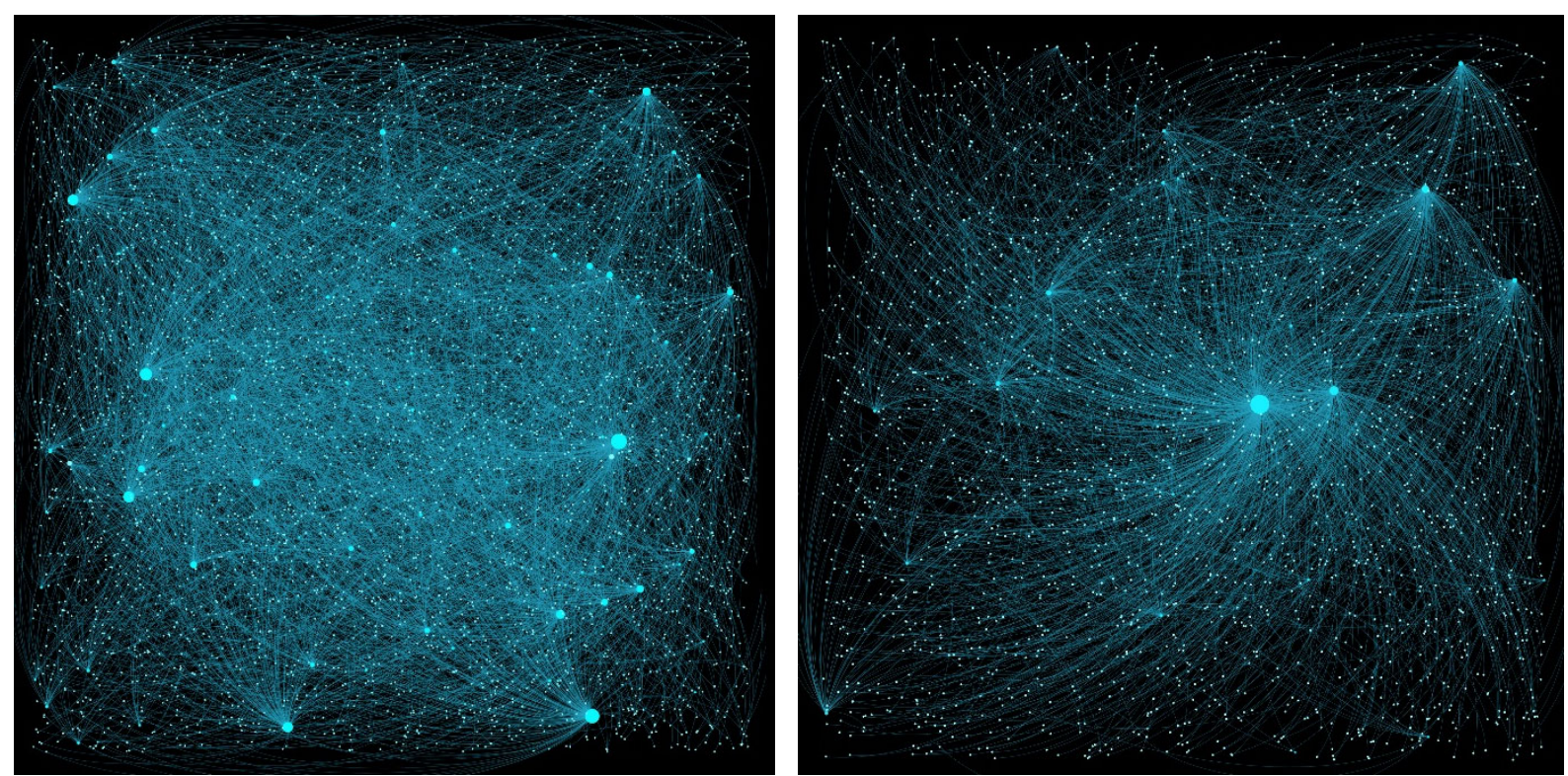

Figure 9. Network centrality: diagrams visualising the variation in network centrality between pre-lockdown (left) and lockdown (right) (J. J. Rong, J. Y. Ye and M. Manfredini, 2020) 

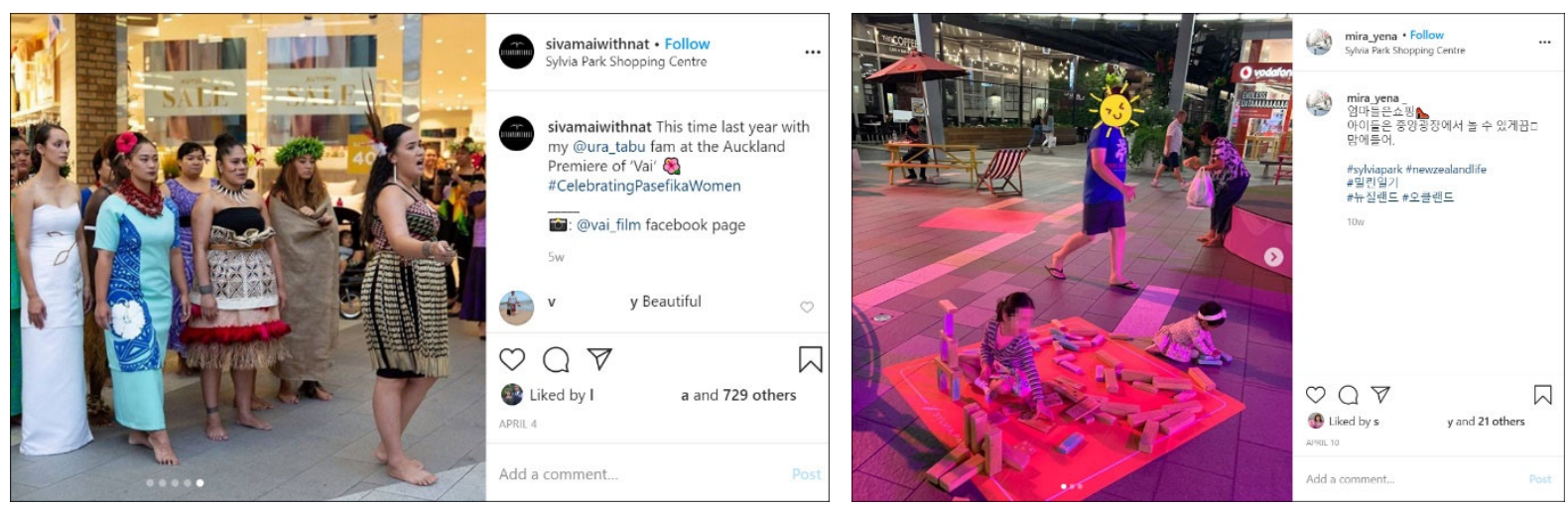

Figure 10. Territorial association: sample of posts (with multiple images) representing strongly associative moments with spatialities of the centre documented before the lockdown (sivamaiwithnat, 2020, left, and mira_yena, 2020, right).

\section{Interpreting the emerging spatialities}

This study was conducted on the digital public space of the best representative case of ultimate apparatus of totalising superlative simulated civicness in the malled urban centres of Auckland, the Ultra-modern Sylvia Park mall. It provided evidence of the formation of novel digitally emplaced relational practices. The documented presence of active emplaced, translocal social networks during the early New Zealand COVID-19 lockdown - an outright negation of public, material, emplaced relational spatialites prompts an affirmative answer to the main research question on the validity of such a study.

Findings on the networks of the digitally enhanced autonomous communities showed minor effects on the continuity and stabilisation during the lockdown period. The sustained commoning activity indicates the outstanding resilience of these networks in effectively negotiating, adapting to, and managing the disruption caused by the lockdown to their relationality.

The comparative network analysis of data provided an affirmative answer also to the first sub-question. Data of the two periods in the ultra-modern mall provided evidence on the actual establishment of the theoretically formulated associative assemblages. They showed that these are able to elude the total control of the apparatuses of the socially adverse civic simulacra that have colonised their commons. The robustness of their translocal operativity documented the maintained intensity of the digitally transductive relationality of their mobilised actors, resources (both tangible and intangible) and relation systems. The comparison between the activities during prelockdown and the lockdown periods showed the vitality of the grassroots networks, which offset the sharp decrease in primary communicative acts (i.e., the lowered number of posts consequent to the interrupted visitation) with a very steep increase in their response ratios in both secondary levels of engagement. This demonstrated efficacy of their mobilisation successfully mitigated the threats of the abrupt transfer of all their operations to the digital component of their spatial emplacements (where the pre-lockdown data are consistent with those a longitudinal research conducted on the same case study).

The comparison of case studies' data showed a notable difference of the activities of the grassroots digital relational networks situated in the modern and ultra-modern centres. 
While under the exacerbated fragmentation agency of the lockdown the networks of the modern centre abated, the meta-stable spatialities of the ultra-modern mall revealed the presence and resilience of collectively produced counterspaces with sustained acts of territorial appropriation and association. Such a difference underlines the sharp transition associated with the creative destruction in the mall sector between the social space of the modern transactional (i.e., shopping-based) centre and the ultra-modern post-consumerist (i.e., pseudo-civic) paradigms. The findings on the role of commercial activity confirm this, showing that the variation in the proportions of this kind of activity in the two types of malls has a limited impact on the activity of grassroots networks. Findings on network analysis were relevant because they not only indicate that the lower number of primary instances had a minor impact on the overall engagement (i.e., ascribed to it the polarisation), but also emphasise the relevance of the social content of posts and comments to foster independent communicative action.

Consistent with the other findings, the content analysis of the representational space in the ultra-modern centre provided evidence to affirmatively answer the second subquestion. The emerging practices in the representational space of the mall showed that the discourses, narratives and practices are efficacious constitutive agents for the reassembling of the mall's destitute commons. These are essential to the institution of the emplaced digital concatenations established by translocal and transductive concrete elements and relation systems.

The locally situated representations (which vastly exceeds the proportion found in the previous longitudinal study on the same area) affirm the composite dimension of social space, articulating the associative capacity of desire through an explicit expression of redistributive orders of ownership and belonging. Portraying recombinant moments of spontaneous appreciation and pleasure, these representations assert the effectiveness of these agents in deconstructing the dominant spatial logics of the simulative infrastructure, elaborating sign values that affirm the right to identification. By supplementing the post-consumerist use-exchange value amalgamation and disbanding the commodity fetishism mechanism of these civic simulacra, these expressions indicate the emerging force of counterterritorial association toward an emancipatory agency of "the pro-active complicity of the citizen consumer" (Miles, 20I2).

Final disclaimer: the COVID 19 lockdown provided evidence of the concurrent implementation and breach of the fundamental rule of non-response of emplacements of superlative abstract civicness designed to manipulate people's practices and actions. This impromptu study on the relational behaviours in the lockdown's exacerbated spatial abstraction supports the theoretically posited critical affirmative interpretation of the emerging post-consumerist urban condition. However, given its multiple limitations, its conclusion should be posited in the form of an opening question in the Foucauldian genealogical tradition: to which extent can the autonomous production of antagonist socio-spatial relational assemblages of the ultra-modern mall avoid to falling prey to the universal alienating normativity that marginalises and displaces antagonist and misaligned groups (Hubbard, 2004), while unrestrainedly dispossess the public and private local entities of their asset's ownership and control (Harvey, 2019)? 


\section{Acknowledgments}

This work was developed as part of the projects "Analysing the Role of Urban Forms in Making Sustainable, Healthy Cities" funded by WUN-World University Network; and "Give Us Space", funded by the National Science Challenge Building Better Homes Towns and Cities of the Ministry of Business, Innovation \& Employment.

\section{References}

Arendt, H. (1958). The human condition. University of Chicago.

Baudrillard, J. (1994). Simulacra and simulation. University of Michigan.

Bueno, A., Chalermtip, T., \& Manfredini, M. (2019). Digital space analysis. https://cpb-apse2.wpmucdn.com/blogs.auckland.ac.nz/dist/b/596/files/2019/08/I .3.I-Digital-SpaceAnalysis-Sylvia-Park-Instagram-SMALL-IMGs.pdf

Butler, S. (1872). Erewhon, or, Over the range. Trübner and Ballantyne.

Cartier, C., Castells, M., \& Qiu, J. L. (2005). The information have-less: Inequality, mobility, and translocal networks in Chinese cities. Studies in Comparative International Development, 40(2), 9-34. https://doi.org//0.I007/BF02686292

de Jong, A., \& Schuilenburg, M. (2006). Mediapolis: Popular Culture and the City. 010 Publishers.

Deleuze, G., \& Guattari, F. (1987). A thousand plateaus: Capitalism and schizophrenia. University of Minnesota Press.

Eco, U. (1986). Travels in hyperreality. Harcourt Brace Jovanovich.

Ferrell, J. (20I I). For a ruthless cultural criticism of everything existing. In J. Ferrell \& K. Hayward (Eds.), Cultural Criminology: Theories of Crime (pp. 558-567). Routledge.

Ferrell, J. (20I3). Cultural Criminology and the Politics of Meaning. Critical Criminology, 2 I(3), 257-27I. https://doi.org/I0.1007/s I06I2-0I3-9I86-3

Foucault, M. (2008). Of other spaces. In M. Dehaene \& L. DE Cauter (Eds.), Heterotopia and the city: Public space in a postcivil society (pp. 13-30). Routledge.

French, S., Leyshon, A., \& Wainwright, T. (201 I). Financializing space, spacing financialization. Progress in Human Geography, 35(6), 798-819.

Goss, J. (1993). The "Magic of the Mall": An Analysis of Form, Function, and Meaning in the Contemporary Retail Built Environment. Annals of the Association of American Geographers, 83(I), 18-47.

Group, K. (n.d.). Sylvia PArk. Retrieved October 8, 2020, from https://www.kiwiproperty.com/corporate/property/sylvia-park/

Guattari, F. (2006). The Anti-Oedipus Papers. In Interpretation A Journal Of Bible And Theology. Semiotext(e).

Harvey, D. (2006). Paris: capital of modernity. Routledge.

Harvey, D. (2007). Neoliberalism as creative destruction. Annals of the American Academy of Political and Social Science, 610(I), 21-44.

https://doi.org/I0.I I77/00027/6206296780 
Hardt, M., \& Negri, A. (2009). Commonwealth. Harvard University Press.

Harvey, D. (20I2). Spaces of capital: Towards a critical geography. Taylor and Francis.

Harvey, D. (2018). Universal alienation. Journal for Cultural Research, 22(2), I37-150. https://doi.org/10.1080//4797585.2018.146/350

Harvey, D. (2019). Rebel cities: from the right to the city to the urban revolution. Verso.

Hoyer, W. D., Kroschke, M., Schmitt, B., Kraume, K., \& Shankar, V. (2020).

Transforming the Customer Experience Through New Technologies. Journal of Interactive Marketing, 5 I, 57-7I. https://doi.org/I0.1016/j.intmar.2020.04.00 I

Hubbard, P. (2004). Revenge and injustice in the neoliberal city: Uncovering masculinist agendas. Antipode, 36(4), 665-689.

Kazig, R., Masson, D., \& Thomas, R. (2016). Atmospheres and mobility. Mobile Culture Studies - The Journal, 3, 7-20.

MacKenzie, A. (2006). Transductions: Bodies and machines at speed. Continuum.

Manfredini, M. (n.d.). Envisioning urban commons as civic assemblages in the digitally augmented city. A critical urbanism exploration of Counterhegemonic Individuation in the Age of Networked translocalism, multiassociative transduction and recombinant transculturalism (A. Taufen \& Y. Yang (eds.)). Routledge.

Manfredini, M. (20I7). The augmented meta-public space: Interpreting emerging transductive territories in enhanced centres of consumption. The Journal of Public Space, 2(3), III-I 28.

Manfredini, M. (2019a). Envisioning atmospheres of spectacle and activism. Utopia and critical urbanism instruments for the reclamation of the fragmented territories of the WALL and the MALL. The Journal of Public Space, 4(4), 83-108.

Manfredini, M. (2019b). Simulation, control and desire: Urban commons and semi-public space resilience in the age of augmented transductive territorial production. The Journal of Public Space, 4(2), I79-198.

Manfredini, M., \& Jenner, R. (20I5). The Virtual Public Thing: de-re-territorialisations of public space through shopping in Auckland's urban space. Interstices: Journal of Architecture and Related Arts, 16, 70-82. https://doi.org// 0.24I35/ijara.v0i0.493

Manfredini, M., Reeves, D., \& Kiddle, R. (2019). Give Us Space: Improving community wellbeing by enhancing performance and communication of semi-public space in the evolving public realm. https://www.drh.nz/labs/urban-relational-informatics/

Manfredini, M., Tian, X., \& Jenner, R. (20I7). "Transductive urbanism" A method for the analysis of the relational infrastructure of malled metropolitan centres in Auckland, New Zealand. Athens Journal of Architecture, 3(4), 4I I-440. 
Miklitsch, R. (1998). From Hegel to Madonna: Towards a general economy of commodity fetishism. State University of New York Press.

Miles, S. (2012). The neoliberal city and the pro-active complicity of the citizen consumer. Journal of Consumer Culture, I2(2), 216-230.

Milgram, P., Takemura, H., Utsumi, A., \& Kishino, F. (1995). Augmented reality: A class of displays on the reality-virtuality continuum. Telemanipulator and Telepresence Technologies. https://doi.org/10.1117/12.197321

Ministry of Health Manatū Hauora. (2020a). Covid-1 9 - Current cases. https://www.health.govt.nz/our-work/diseases-and-conditions/covid-19-novelcoronavirus/covid-19-current-situation/covid-19-current-cases\#probable

Ministry of Health Manatū Hauora. (2020b). COVID- 9 (novel coronavirus). https://www.health.govt.nz/our-work/diseases-and-conditions/covid-I9-novelcoronavirus

Ministry of Health Manatū Hauora. (2020c). Section 70(I)(f) Health Act Order (COVID-19 Alert Level 4) 24/03/2020. https://covid I 9.govt.nz/assets/resources/legislation-andkey-documents/COVID-I9-Section-70If-Notice-to-all-persons-in-New-Zealand-3April-2020.PDF

Mouffe, C. (1999). Deliberative democracy or agonistic pluralism? Social Research, 6(3), 745-758.

OECD. (2020). Organisation for Economic Co-operation and Development: Informality and social protection in the time of COVID-19. Governing Board Thematic Session on COVID19 \& social resilience. http://www.oecd.org/dev/HLM-Thematic-note-Informalitysocial-protection-post-COVID-19.pdf

Pine, B. J., \& Gilmore, J. H. (20I I). The experience economy. Harvard Business Review Press.

Ritzer, G. (20I4). Prosumption: Evolution, revolution, or eternal return of the same? Journal of Consumer Culture, I4(I), 3-24.

Ritzer, G., \& Degli Espositi, P. (2020). Creative destruction and cultural lag in the digital age. Sociology Between the Gaps: Forgotten and Neglected Topics, 5. https://digitalcommons.providence.edu/sbg/vol5/iss I/5

Ritzer, G., \& Jurgenson, N. (20I0). Production, consumption, prosumption. Journal of Consumer Culture, 10(1), I3-36. 
Ritzer, G., \& Lair, C. (2007). Outsourcing: Globalization and Beyond. In G. Ritzer (Ed.), The Blackwell Companion to Globalization (pp. 307-329). Blackwell.

Shane, G. (2005). Recombinant urbanism: Conceptual modeling in architecture, urban design, and city theory. Wiley.

Sloane, M. (2020). Inequality in the digital pandemic. Social Science Research Council, Insights Form the Social Sciences. https://items.ssrc.org/covid-19-and-the-socialsciences/society-after-pandemic/inequality-in-the-digital-pandemic/

Statcounter, G. S. (2020). Social media stats New Zealand. https://gs.statcounter.com/social-media-stats/all/new-zealand

Stats NZ Tatauranga Aotearoa. (2020). Earnings for people in paid employment by region, sex, age groups and ethnic groups. http://nzdotstat.stats.govt.nz/wbos/Index.aspx?DataSetCode=TABLECODE747 I\#

Tan, L. (2020). Covid 19 coronavirus: Auckland Night Markets to start delivery operations at level 3. https://www.nzherald.co.nz/nz/covid-19-coronavirus-auckland-nightmarkets-to-start-delivery-operations-at-level3/YMDUO6L2XYX6ENP7IVVY6SDJFE/

Terruhn, J. (2020). Urban diversity and inequality in Auckland. In R. Simon-Kumar, F. Collins, \& W. Friesen (Eds.), Intersections of Inequality, Migration and Diversification. Mobility \& Politics (pp. |3|-|5|). Palgrave Pivot.

The Treasury Te Tai Ōhanga. (2020). The Treasury Te Tai Ōhanga. https://treasury.govt.nz/sites/default/files/2020-05/covid-19-econ-dashboard29may2020.pdf

URIL. (n.d.). Urban Relational Informatics Lab. Retrieved October 8, 2020, from https:/www.drh.nz/labs/urban-relational-informatics/

Voyce, M. (2006). Shopping malls in Australia: The end of public space and the rise of “consumerist citizenship"? Journal of Sociology, 42(3), 269-286.

https://doi.org/ I0. I I77//440783306066727

WHO. (2020). New Zealand takes early and hard action to tackle COVID-19. World Health Organisatoin - Western Pacific. https://www.who.int/westernpacific/news/featurestories/detail/new-zealand-takes-early-and-hard-action-to-tackle-covid-19

Wilson, N., Boyd, M., Teng, A., \& Blakely, T. (2018). A century of health inequalities in NZ—New data. https://blogs.otago.ac.nz/pubhealthexpert/2018/03/26/a-century-ofhealth-inequalities-in-nz-new-data/ 